OPEN ACCESS

Edited by: Kaiqiang Zhang,

Imperial College London, United Kingdom

Reviewed by:

Pat Brady,

Sandia National Laboratories,

United States

Fajian Nie,

Zhengzhou Zoo, China

*Correspondence:

Yanyu Zhang

yyzhang@upc.edu.cn

Xuemei We

307725687@qq.com

Specialty section:

This article was submitted to Advanced Clean Fuel Technologies,

a section of the journal

Frontiers in Energy Research

Received: 30 August 2020

Accepted: 26 October 2020

Published: 20 November 2020

Citation:

Wei $X$, Jiang $W$, Zhang $Y$, Wang Z, Li X and Wu $F$ (2020) Investigation of Clay

Type on Low Salinity Water Flooding

Using a Glass Micromodel.

Front. Energy Res. 8:600448.

doi: 10.3389/fenrg.2020.600448

\section{Investigation of Clay Type on Low Salinity Water Flooding Using a Glass Micromodel}

\author{
Xuemei Wei ${ }^{1,2 *}$, Wenchao Jiang ${ }^{1,2}$, Yanyu Zhang ${ }^{1,2 *}$, Zhao Wang ${ }^{1,2}$, Xiaojun $L i^{3}$ and \\ Feipeng $W u^{1,2}$
}

${ }^{1}$ Key Laboratory of Unconventional Oil and Gas Development, China University of Petroleum East China, Ministry of Education, Qingdao, China, ${ }^{2}$ School of Petroleum Engineering, China University of Petroleum (East China), Qingdao, China, ${ }^{3}$ Dongxin Oil Production Plant, Shengli Oilfield, Dongying, Shandong, China

Clay minerals are usually regarded as an important factor affecting the results of low salinity water (LSW) flooding. However, experiments on clay minerals are mainly in qualitative stage, the mechanism of clay minerals has not been studied completely. In this paper, Zeta potential of four kinds of clay minerals (montmorillonite; chlorite; illite; kaolinite) in different brine was measured, microscopic models of these clay minerals were made to measured wetting angle in different brine, and montmorillonite and kaolinite were chosen to conduct microscopic displacement experiments through customized micro-glass etching models. From experiment results, the following conclusions can be get: 1). With the decrease of salinity of injected water, the negative zeta potential of clay minerals increases and the wetting angle decreases. 2). Clay minerals are more sensitive to monovalent $\mathrm{Na}^{+}$than bivalent $\mathrm{Ca}^{2+}$. 3). The results of microscopic experiments show that LSW can effectively improve oil recovery, whether kaolinite or montmorillonite. The recovery of montmorillonite is better with a relatively high salinity of LSW and kaolinite is better with a relatively low salinity of LSW. The mechanism of LSW improves kaolinite recovery factor is the change of wettability while that of montmorillonite is the increase of water phase wettability. However, a lot of droplet-like residual oil cannot be displaced in the montmorillonite throat. In filed production, both kaolinite-rich and montmorillonite-rich reservoirs are suitable for LSW flooding to improve oil recovery. However, for kaolinite reservoirs, a lower salinity of injected water would produce a better result, while for montmorillonite reservoirs, residual oil droplets in the throat are noteworthy.

Key words: low salinity water flooding, clay minerals, wettability, zeta potential, micro displacement

\section{INTRODUCTION}

With the exploitation of oil and gas resources, the development of oilfield becomes more and more difficult. It requires new and effective enhanced oil recovery (EOR) methods. As an emerging oil recovery technology, the popularity of low salinity water (LSW) is mainly caused by its low cost, environmental-friendly and easy operation, all of which being economic benefits compared with chemical EOR methods (Lager et al., 2008; Al Shalabi et al., 2014; Nasralla and Nasr-El-Din, 2014a; Reed and Mcdonald, 2015). LSW flooding can increase oil recovery by $8-12 \%$ and up to $40 \%$ on secondary recovery (Lager et al., 2008). 
TABLE 1 | Composition of $\mathrm{Na}^{+}$and $\mathrm{Ca}^{2+}$ Solutions (mg/L).

\begin{tabular}{lcccccc}
\hline $\mathbf{N o}$ & $\mathbf{N a}^{+}$ & $\mathbf{C a}^{\mathbf{2 +}}$ & $\mathbf{K}^{+}$ & $\mathbf{M g}^{\mathbf{2 +}}$ & $\mathbf{C l}^{-}$ & $\mathbf{S O}_{\mathbf{4}}{ }^{\mathbf{2}}$ \\
\hline 1 & 500 & 0 & 50 & 50 & 550 & 50 \\
2 & 1,000 & 0 & 100 & 100 & 1,100 & 100 \\
3 & 5,000 & 0 & 500 & 500 & 5,500 & 500 \\
4 & 10,000 & 0 & 1,000 & 10,000 & 11,000 & 1,000 \\
5 & 20,000 & 0 & 2000 & 2000 & 22,000 & 2000 \\
6 & 0 & 500 & 50 & 50 & 1,050 & 50 \\
7 & 0 & 1,000 & 100 & 100 & 2,100 & 100 \\
8 & 0 & 5,000 & 500 & 500 & 10,500 & 500 \\
9 & 0 & 10,000 & 1,000 & 1,000 & 21,000 & 1,000 \\
10 & 0 & 20,000 & 2000 & 2000 & 42,000 & 2000 \\
\hline
\end{tabular}

LSW flooding can alter physical and chemical properties of reservoir by injecting water with a low concentration of soluble ions. It can reduce the saturation of residual oil and improve oil recovery. The EOR mechanism of LSW flooding is pretty complex. Meanwhile, it is generally believed that clay minerals in reservoir rocks are important factors that would affect the result of LSW flooding (Tang and Morrow, 1999; Zhang et al., 2007; Loahardjo et al., 2010; Tina et al., 2018; Zhang et al., 2018). Lots of studies on the influence mechanisms of clay minerals in LSW flooding were conducted (Barnaji et al., 2016; Al-Saedi et al., 2018).

The main mechanism of LSW flooding on enhancing oil recovery includes the migration of particles (Tang and Morrow, 1999) and changes in wettability (Zhang et al., 2007; Demir et al., 2016; Al-Saedi and Flori, 2018; Zhang et al., 2018). Tang and Morrow, (1999) first discovered that the migration of clay mineral particles is an important factor for the flooding of residual oil adsorbed on the pore wall. Kim and Lee, (2017) studied the influence of clay type on relative permeability changes in LSW flooding, results show that the difference of relative permeability curve between conventional water flooding and LSW flooding is related to the type of clay minerals. The moving range of the relative permeability curve in kaolinite was proportional to clay contents. Although the moving range in illite showed similar characteristics, it was not as obvious as that in kaolinite. As a result, they thought the existence of kaolinite has a positive effect on oil recovery in LSW flooding and the influence of illite was negligible. Fogden et al., (2011) designed sandstone core displacement experiments, which illustrated that the principle of enhancing recovery by LSW is the migration of clay particles.

As for changes in wettability, Zhang et al., (2007), Zhang et al., (2018) measured contact angle on core slices and Zeta potential of rock particles, their results showed that the impact of clay minerals on oil recovery under LSW is the reduction of contact angle. Lager et al., (2008) proposed that the cation exchange from LSW to rock surface was the main reason for the change of wettability and improved recovery. LSW can absorb organic compounds and organic metal
TABLE 2 | Physical properties and components of crude oil.

\begin{tabular}{llc}
\hline The oil samples & \multicolumn{2}{c}{ GD2-23X602 } \\
\hline Components/wt\% & Saturated hydrocarbons & 36.12 \\
& Aromatics & 31.13 \\
& Resin & 22.42 \\
& Asphaltene & 10.33 \\
Viscosity/(mPa.s) & $50^{\circ} \mathrm{C}$ & 5,080 \\
& $60^{\circ} \mathrm{C}$ & 2,530 \\
& $70^{\circ} \mathrm{C}$ & 1,290 \\
& $80^{\circ} \mathrm{C}$ & 690 \\
\hline
\end{tabular}

complexes on clay surface and replace them with simple cations to increase the hydrophilicity of the rock surface. Hilner et al. (2015) believed the diffusion of the doubleelectron layer played an important role in the change of wettability. With the decrease of the salinity of injected fluids, the expansion of the double-electron layer reduced the attraction of organic molecules to the rock surface and changed the wettability of rock.

Yousef et al. (2011) thought the key to improve recovery with LSW is the change of wettability of rock surface by core displacement experiments. Tammy and Manouchehr (2018) indicated that the exchange of cation from LSW to rock surface has a significant effect on the change of wettability. Stanislav et al., (2018) found that the surface charge of clay minerals is a key factor in LSW flooding experiments. Results from in situ ATR-FITR experiments emphasized that the exchange of cation between formation water and LSW is an important step in changing reservoir wettability, and the build of cation bridges between organic compounds and clay mineral surface that decrease repulsive forces between negative solutes and negative reservoir surfaces is essential for LSW flooding EOR.

Under different conditions, study results differ from each other greatly due to the influence of the occurrence mode of clay minerals and fluid properties. Meanwhile, the EOR mechanism varies a lot among different clay minerals and is rarely studied. Therefore, four kinds of clay minerals (montmorillonite, illite, kaolinite, chlorite), which are primary clay minerals in sandstone reservoirs, are selected in this paper. Through the measurement of Zeta potential, diffusion mechanism of the double-electron layer is analyzed from the angle of van der Waals force and electrostatic force. Besides, to analyze the mechanism behind the change of wettability, wetting angle measurement of clay mineral foil is carried out systematically. At the same time, micro-seepage characteristics of LSW flooding under customized mineral surface were studied by using two different kinds of clay minerals, kaolinite and montmorillonite. EOR mechanisms of LSW flooding with different clay minerals are characterized by morphological changes and dynamic distribution rules of crude oil, water and residual oil in the pore channel during water flooding, and further suggestions are made for field production. 
TABLE 3 | Characterization of different clay minerals.

\begin{tabular}{lcccc}
\hline Specification & Montmorillonite & Kaolinite & Illite & Chlorite \\
\hline Chloride $(\mathrm{Cl}) /$ mass $\%$ & $<0.025$ & $<0.025$ & $<0.02$ & $<0.03$ \\
Sulfate $\left(\mathrm{SO}_{4}\right) /$ mass $\%$ & $<0.1$ & $<0.1$ & $<0.1$ & $<0.1$ \\
Heavy metals/mass $\%$ & $<0.005$ & $<0.005$ & $<0.005$ & $<0.005$ \\
Loss on drying/mass $\%$ & $<0.2$ & $<0.15$ & $<0.1$ & $<0.15$ \\
CEC $($ meq/100g) & 95 & 4.3 & 32 & 20 \\
Average particle size/ $\mu \mathrm{m}$ & 3.4 & 3 & 2.9 & 3.2 \\
\hline
\end{tabular}

\section{EXPERIMENT}

\section{Material}

\section{Low Salinity Water}

To determine the influence of ion type and concentration of low salinity water on clay minerals, we used distilled water without any ionic to prepare $\mathrm{NaCl}$ and $\mathrm{CaCl}_{2}$ solutions with the $\mathrm{Na}^{+}$and $\mathrm{Ca}^{2+}$ concentrations of $500 \mathrm{mg} \mathrm{L}^{-1}, 1,000 \mathrm{mg} \mathrm{L}^{-1}, 5,000 \mathrm{mg} \mathrm{L}^{-1}$, $10,000 \mathrm{mg} \mathrm{L}^{-1}$, and $20,000 \mathrm{mg} \mathrm{L}^{-1}$, respectively. And the detailed composition of these solutions are shown in Table 1.

\section{Crude Oil}

Oil used in this experiment is crude oil from Shengli Oilfield. Composition and basic physical properties of the oil can be seen in Table 2. Its viscosity, colloid and asphaltene are pretty high, which makes it belong to the heavy oil.

\section{Clay Minerals}

Clay minerals used in experiments were from Shendeng Chemistry company. X-ray diffraction (XRD) was conducted to characterize their mineral compositions. Also, CEC of them were measured through the methylene blue test. Specifications of them are presented in Table 3. From this table we can see that the montmorillonite has the highest CEC value, indicating its highest swelling potential among these minerals. A higher CEC value of the clay mineral means its surface can carry more electric charges, and the surface electronegativity will be stronger after dissociation. Montmorillonite carries permanent negative charge mainly through lattice substitution, and its cation exchange capacity is largest among these clay minerals. Although illite is similar to montmorillonite in structure, which is charged by lattice substitution, there are ionic bonds and molecular bonds between crystal layers and cations are not easily replaced by strong electrostatic force. As a result, negative charge of illite is less than that of montmorillonite. Charge between crystal layers of kaolinite has reached equilibrium, so it is not easy for the occurrence of lattice substitution. Compared with montmorillonite and illite, kaolinite has a lesser negative charge. As for chlorite, it has the lowest negative, so its cation exchange capacity is the worst.

To determine the effects of different clay minerals, quartzsand with a granularity of 200 mesh, which is the largest mesh can float in solution, and four clay minerals (montmorillonite, kaolinite, chlorite and illite) were selected for the Zeta potential measurement experiments. Quartz-sand with a granularity of 1,250 mesh, which is well attached to the micromodel, and four clay minerals (montmorillonite,
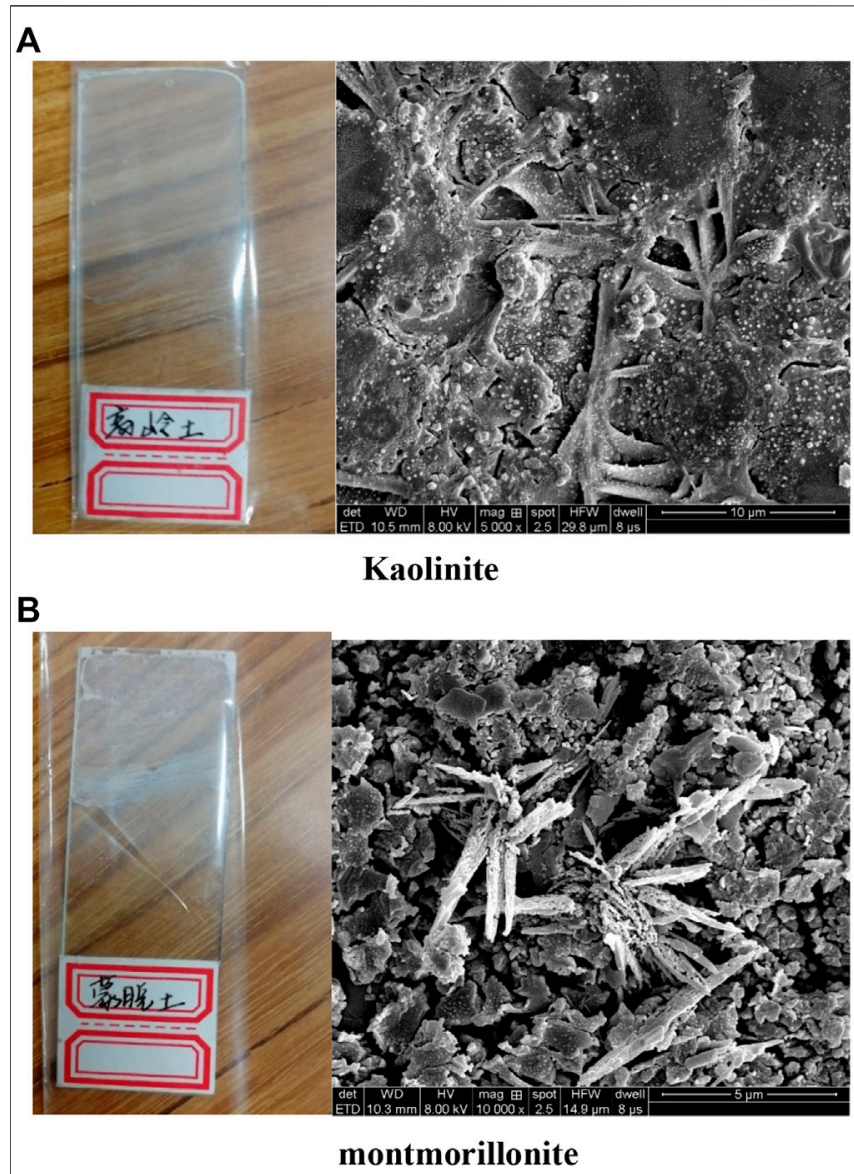

FIGURE 1 | Clay coated glass slide and SEM images.

kaolinite, chlorite and illite) were selected for the wetting angle measurement and microscopic displacement experiments.

To coat micromodel with clay minerals, a slurry made of clay particles and high salinity water (HSW), whose $\mathrm{Na}^{+}$ concentration is $20,000 \mathrm{mg} \mathrm{L}^{-1}$, was injected into the micromodel. And optimized concentration of clay in the suspension is $20 \mathrm{wt} \%$. Before injection, to obtain a homogeneous solution, the mixture was stirred for $20 \mathrm{~min}$, followed by sonication for $0.5 \mathrm{~h}$, to prevent flocculation from occurring. To avoid the settlement and clog of clay and ensure a quasi-homogeneous distribution of clay in the micromodel, a syringe pump with a rate of $20 \mathrm{~m}$ /day was used for slurries with different pore volumes in the injection process.

In most reported work, after slurry injection, micromodels would be heated in ovens for $72 \mathrm{~h}$ under $80^{\circ} \mathrm{C}$ (Bondino et al., 2013). However, heat-dried clay minerals will lead to irreversible clay coating, which means that clay particles would be left on the surface and they would be immobile and unresponsive to any changes that happened in the displacement experiment. To avoid this issue, models were placed on an $80^{\circ} \mathrm{C}$ plate and were hot-airdried for $2 \mathrm{~h}$ (Amirian et al., 2017). Interfacial tension between air and water phases would dislodge blocked throats and the moderate temperature of the hot plate would assist with the drying process. 


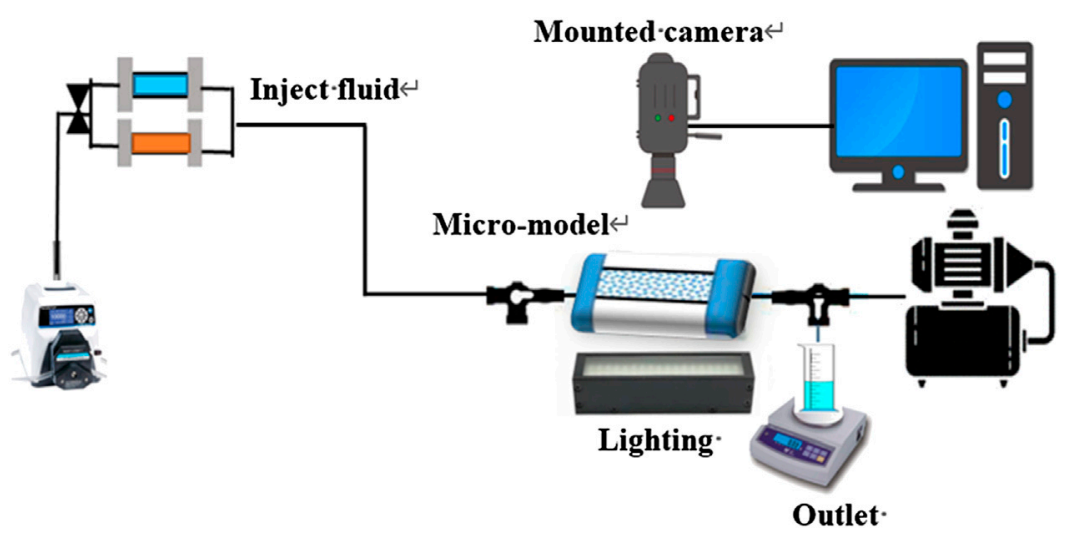

FIGURE 2 | Microscopic visual model displacement experimental device.

\section{Zeta Potential Determination}

Nano Brook 90Plus Pals Zeta potential and granularity analyzer was used in Zeta potential determination experiments. We weighed accurately $1 \mathrm{~g}$ purified 200-mesh quartz-sand, montmorillonite, kaolinite, chlorite and illite, dispersed them into $200 \mathrm{ml} \mathrm{NaCl}$ and $\mathrm{CaCl}_{2}$ solutions with $\mathrm{Na}^{+}$and $\mathrm{Ca}^{2+}$ ionic concentrations of $500 \mathrm{mg} \mathrm{L}^{-1}, 1,000 \mathrm{mg} \mathrm{L}^{-1}, 5,000 \mathrm{mg} \mathrm{L}^{-1}$, $10,000 \mathrm{mg} \mathrm{L}^{-1}$ and $20,000 \mathrm{mg} \mathrm{L}^{-1}$, respectively, then used a magnetic stirring to stir under $30^{\circ} \mathrm{C}$ for $15 \mathrm{~h}$ and let stand for $24 \mathrm{~h}$. After that, we measured the Zeta potential value of quartzsand and clay-salt water under room temperature.

\section{Measurement of Wetting Angles}

Experiments were carried out using the SL200KS wetting angle and interface tensiometer. Micromodel mentioned in Clay Minerals was used to measure the wetting angles. Besides, a JSM-IT200 scanning electron microscope was used to scan micromodels at a scale of $10 \mu \mathrm{m}$. Completed models and scanned figures are shown in Fig 1. Vacuumed the pressed clay flakes, saturated crude oil, then aged for $24 \mathrm{~h}$ as the standby. Above solutions were taken separately in the injection pump, and different kinds of saline water droplets were dropped onto the surface of clay models with a high-precision injection pump. Then, the wetting angles were measured after $2 \mathrm{~h}$ of stabilization. The measurement aimed to study the influence of brine salinity and clay minerals on rock-wettability alteration.

\section{Experiment of Microscopic Displacement}

In order to study the seepage characteristics of LSW flooding at the micro-model scale and verify the mechanism of LSW flooding, the influence of clay type on seepage characteristics of LSW was studied by two-dimensional glass micro-model and pore-scale visualization method.

Montmorillonite and kaolinite were selected as representatives of swelling clay and non-swelling clay to carry out the microscopic displacement experiments, and experiments were carried out using the experimental instrument showed in Fig 2. A mixture of clay minerals and brine with a salinity of $20,000 \mathrm{mg} \mathrm{L}^{-1} \mathrm{NaCl}$ was injected into the micromodel.

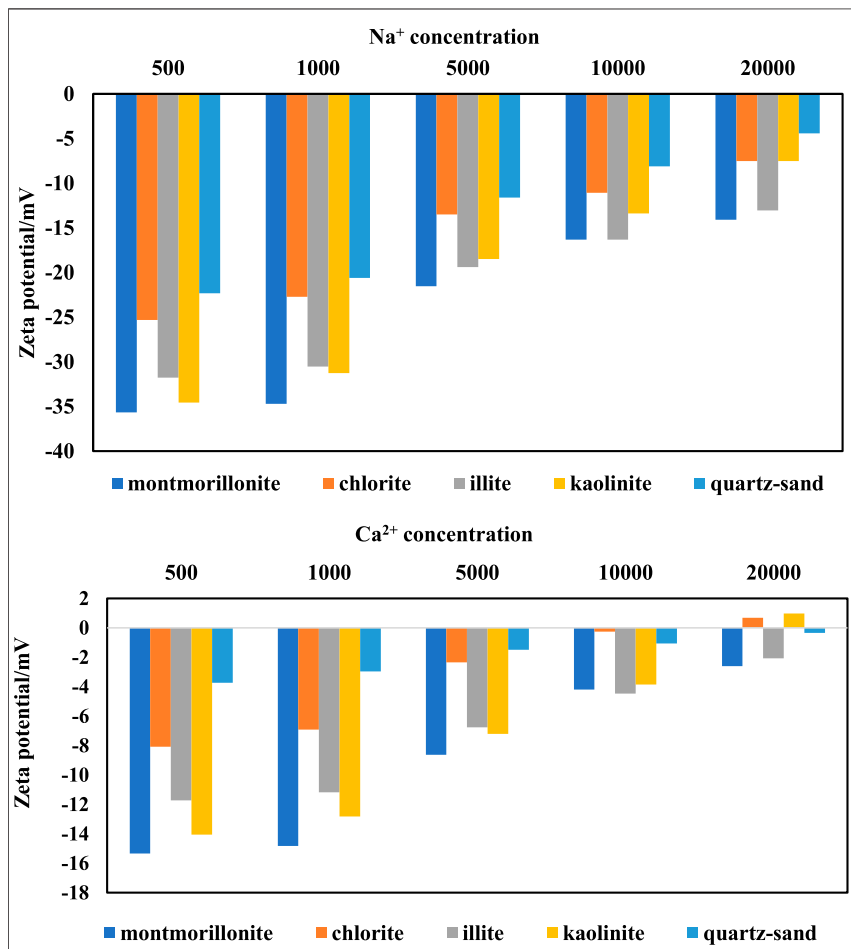

FIGURE 3 | Zeta potential of different kinds of clay minerals.

Afterward, the micromodel was hot-air dried and clay-coated model was saturated first with $\mathrm{HSW}\left(20,000 \mathrm{mg} \mathrm{L}^{-1} \mathrm{NaCl}\right)$ and then crude oil. Then, put the micromodel for 1week under $80^{\circ} \mathrm{C}$ for aging purpose.

After the aging process, HSW was injected at a rate of $0.2 \mathrm{ml} \mathrm{min}-1$ as designed. When there is no crude oil in the produced fluid, HSW was injected at a rate of $0.2 \mathrm{ml} \mathrm{min}^{-1}$ until there is no increase in water saturation, then, injected the LSW at a rate of $0.2 \mathrm{ml} \mathrm{min}^{-1}$. The $\mathrm{pH}$ value of the brine used in the experiment was 7. A microscope was used to observe and record changes in the oil and water interface in the pore space. The 
microscope provides visual evidence for migration characteristic changes.

\section{RESULTS AND DISCUSSION}

\section{Results and Discussion of Zeta Potential Measurement}

Zeta potential is the potential on the boundary sliding surface of the electric double layer, and it is positively correlated with the electrostatic repulsion force. Therefore, Zeta potential is used to represent the surface potential of clay particles (Kaya et al., 2006). Results of Zeta potential measurement are shown in Fig 3.

With the increase of the concentration of $\mathrm{Na}^{+}$and $\mathrm{Ca}^{2+}$, the negative values of Zeta potential of quartz sand-brine interface and clay mineral-brine interface gradually decrease. This is because clay particles are negatively charged and have an adsorption effect on cations. When the concentration of cation increases, more cations enter into the tight layer through the diffusion layer, and the ability to neutralize the negative charge on clay surface is enhanced. As a result, the absolute value of Zeta potential on the surface of quartz sand and clay mineral particles gradually decrease (Kaya et al., 2006). In addition, Zeta potential values of different kinds of clay minerals in the same brine are different, and the negative Zeta potential values of clay mineralsbrine interface are almost larger than those of quartz sand-brine, and the negative values of Zeta potential of quartz sand and clay minerals from large to small are: montmorillonite $>$ kaolinite $>$ illite $>$ chlorite. Different ions have different effects on Zeta potential. For quartz sand and clay minerals in solutions with the same concentration of $\mathrm{Na}^{+}$and $\mathrm{Ca}^{2+}$, the negative value of Zeta potential in $\mathrm{NaCl}$ solution is larger than that in $\mathrm{CaCl}_{2}$ solution, and the variation magnitude of Zeta potential shows the same relationship. This is because the divalent $\mathrm{Ca}^{2+}$ ions can compress the diffusion layer on the surface of quartz sand and clay mineral particles more easily than the monovalent $\mathrm{Na}^{+}$ions in a brine solution with the same ion concentration, and the thickness of the diffusion layer decreases as a result. The $\mathrm{Ca}^{2+}$ ions enter into the adsorption layer from the diffusion layer, which neutralizes more negative charges on the surface of particles, resulting in a decrease of the negative Zeta potential. At the same time, the potential reversal of kaolinite and chlorite happens in the environment of high $\mathrm{Ca}^{2+}$ concentration. The reason is that kaolinite and chlorite carry less negative charge because of their lattice structure and charging characteristics. With the increase of the concentration of $\mathrm{Ca}^{2+}$ ions, the concentration of counter ion $\mathrm{Ca}^{2+}$ around the particle surface increases continuously, which compresses the diffusion layer and pushes more $\mathrm{Ca}^{2+}$ into the slipping plane and makes the negative value of Zeta potential on the particle surface decrease continuously, and finally makes the Zeta potential positive.

Through the Zeta potential measurement experiment, it can be inferred that the injection of LSW will increase the negative value of Zeta potential and increase the thickness of the diffusion layer in the double electron layer on the surface of clay minerals, which

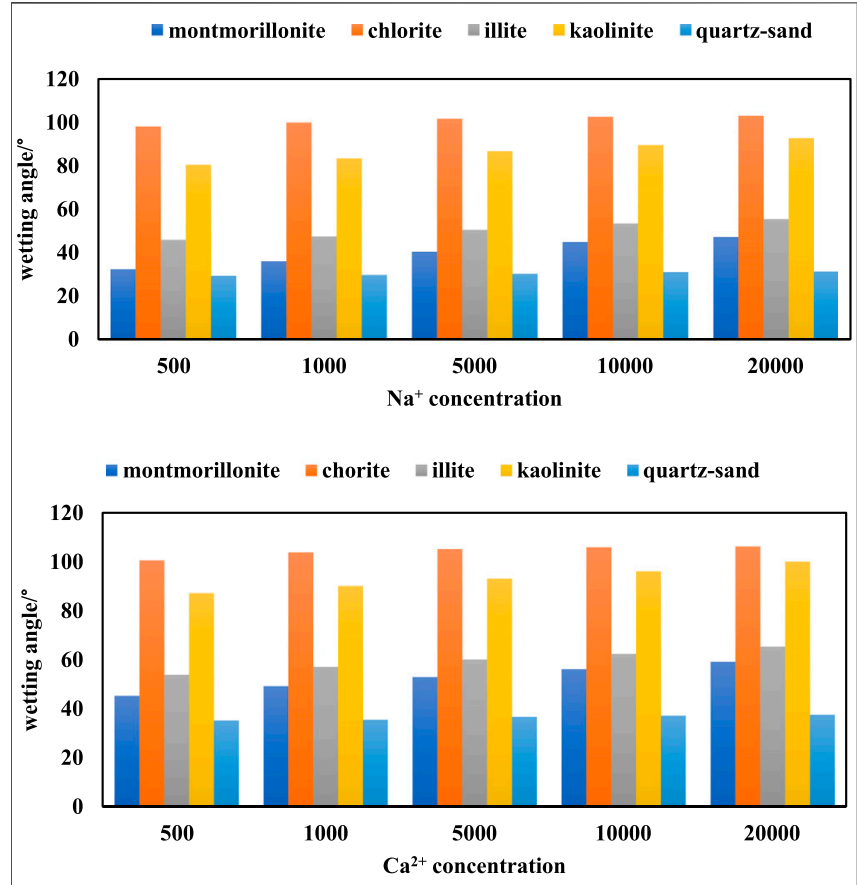

FIGURE 4 | Wetting angle of different kinds of clay minerals.

makes the oil with negative electricity easily desorb from the rock surface attached with clay minerals. Therefore, double electron layer diffusion is the main mechanism of the LSW flooding effect.

\section{Results and Discussion of Wetting Angle Measurement}

Wetting angle between the oil-water-mineral was measured in the experiment. The wettability of reservoir rock depends on the stability of the thin brine film that wets its surface. The stability of the film is influenced by interactions between its brine-rock and oil-rock interfaces which are described by classical DLVO theory (Myint and Firoozabadi, 2015).

Wetting angles of quartz sand - brine interface are shown in Fig 4. From this figure, we can see that the LSW can effectively reduce the wetting angle of minerals. The wetting angle is a function of decomposition pressure which is composed of the expansion force of the double electron layer, Van Der Waals force and structural force (Hirasaki, 1991). The decrease of the ion concentration makes Zeta potential of clay-brine interface strongly negative (Nasralla and Nasr-El-Din, 2014b), forming a thick double electron layer, increasing the electrostatic repulsion force on the surface of simulated oil and clay (Xie et al., 2016), reducing the wetting angle and increasing the hydrophilicity.

Wetting angle of droplets on the surface of quartz sand and different types of clay flakes varies with the change of droplet salinity. With the increase of droplet salinity, the wetting angle of quartz sand and different types of clay flakes gradually increased, as a result, water wettability decreased and oil wettability increased. As shown by the results, the change of wetting 
Oil is wetting phase and oil left on the oil-wet surface

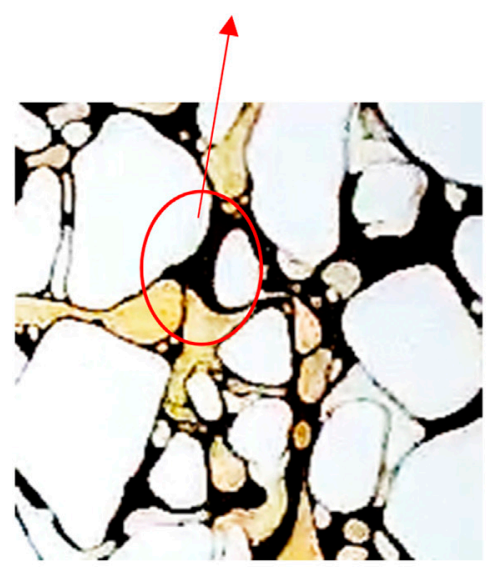

(1) after HSW injection
Menisci moves toward to the surface and replaces the oil

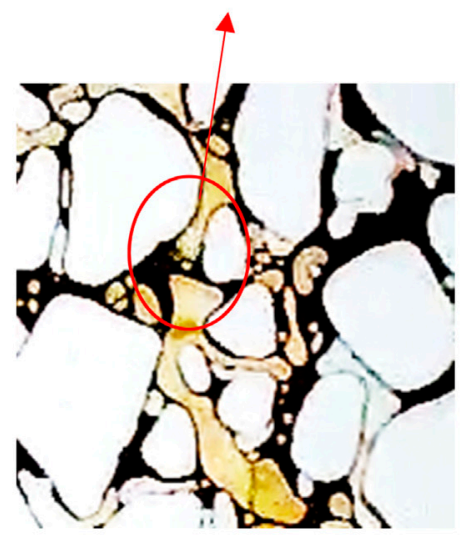

(2) during LSW injection
Oil is completely replaced by LSW and wetting phase become water-wet

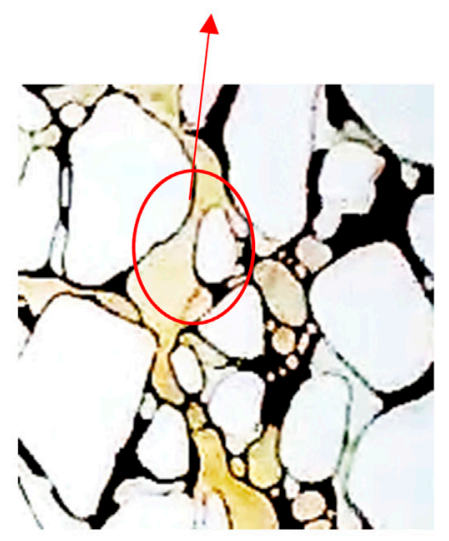

(3) after LSW injection

FIGURE 5 | Kaolinite coated micromodel during displacement.

angle is caused by the different amounts of negative charge in HSW and LSW. HSW produced weak charges at the oil-water and rock-water interfaces, which lead to the weak repulsive force between the oil and rock system and resulted in a stable water film and a less water-wet system. On the contrary, LSW increased the magnitude of the negative charges. An increase in the magnitude of the negative charge at oil-water and rock-water interfaces resulted in a higher repulsive force between oil and rock, which expanded the double layer and produced a more waterwet system.

Comparing the wetting angles of quartz sand and clay minerals in $\mathrm{NaCl}$ and $\mathrm{CaCl}_{2}$ solutions, it can be found that the wetting angles of quartz sand and clay minerals of $\mathrm{CaCl}_{2}$ solution droplets are larger than that of $\mathrm{NaCl}$ solution droplets under the same ion concentration. This indicates that the ionic valence state adsorbed by clay minerals in aqueous solution affects the thickness of hydration film, when the ionic valence state is lower, the hydration film will be thicker and the water wettability will be stronger. Since the valence of $\mathrm{Ca}^{2+}$ is larger than that of $\mathrm{Na}^{+}, \mathrm{Ca}^{2+}$ will carry more positive charges than $\mathrm{Na}^{+}$ under the same solution concentration, which can neutralize more negative charges on the surface of quartz sand, clay sheet and simulated oil surface. The negative value of the Zeta potential is smaller. Consequently, the diffusion layer in the double electron layer is compressed to a greater extent, showing a weaker negative charge, and the electrostatic repulsion force is smaller. The ability of the oil to fall from the surface of quartz sand and clay minerals is weaker. As a result, the wettability of $\mathrm{CaCl}_{2}$ solution on the surface of quartz sand and clay minerals is weaker than that of $\mathrm{NaCl}$ solution, the oil wettability is stronger and the wetting contact is larger.

\section{Results and Discussion of Micro Displacement Low Salinity Water Flooding in Kaolinite}

The clay-coated model was first saturated with LSW $\left(20,000 \mathrm{mg} \mathrm{L}^{-1} \mathrm{NaCl}\right)$ and then crude oil. Before saturated with crude oil, the porous medium was completely water-wet since kaolinite is highly hydrophilic and the presence of salt enhances the water wettability considerably. When the claycoated model with kaolinite was saturated by crude oil under formation water environment, surface charges of kaolinite and crude oil were neutralized by the oppositely charged ion in the formation water, the electrostatic repulsion between the rock-oil interfaces decreased and the brine film was destabilized. Then the polar components of crude oil adhered to the surface of clay particles, making the surface of clay particles more oil-wetting.

As illustrated in Fig 5, dynamics of two-phase flow were visualized. In the oil-wet porous medium, during the injection of LSW, the moving mechanism was observed and the oil-water interface moved through narrow throats to large pores, displacing the wetting phase (oil phase).

After the injection of HSW, as shown in Fig 5. 1), the whole system was oil-wet and the oil phase cannot flow from the rock surface, which resulted in the low oil recovery efficiency. During the injection of LSW, as shown in Fig 5. 2), wetting properties of pores changed from oil-wet to mixed wetting. The meniscus was continuously advanced, leaving the oil film attached near the wall of the lipophilic hole. However, on the hydrophilic surface, the interface moved toward the surface of kaolinite particles, replacing the oil film, so the amount of oil in pores was reduced significantly. After the injection of LSW, as shown in Fig 5. 3), the water-oil menisci displaced oil in many small pores. 

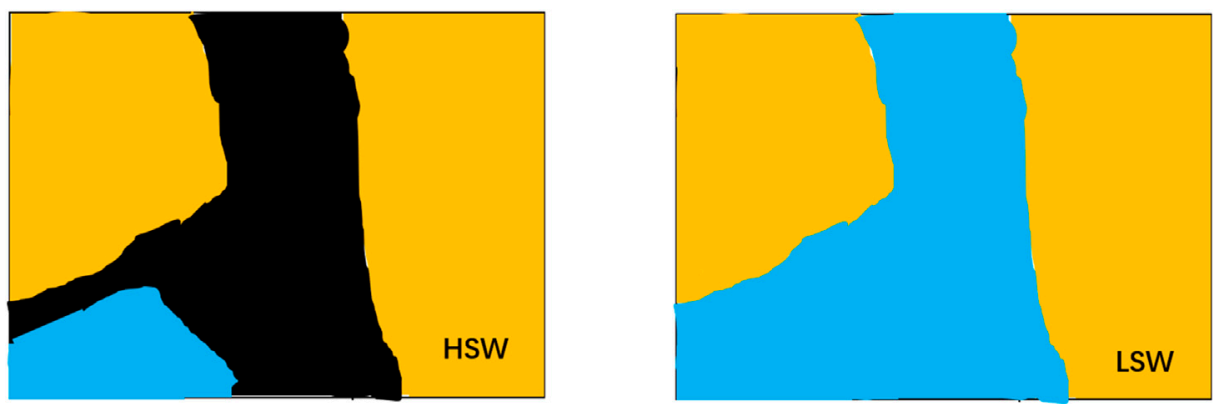

rock

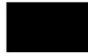

oil

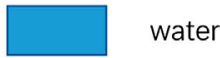

FIGURE 6 | Wetting properties of kaolinite model during high salinity water (HSW) and low salinity water (LSW).

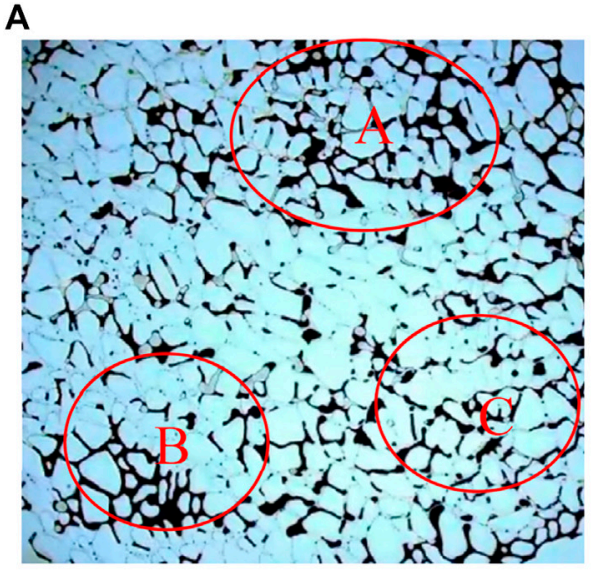

HSW injection
B

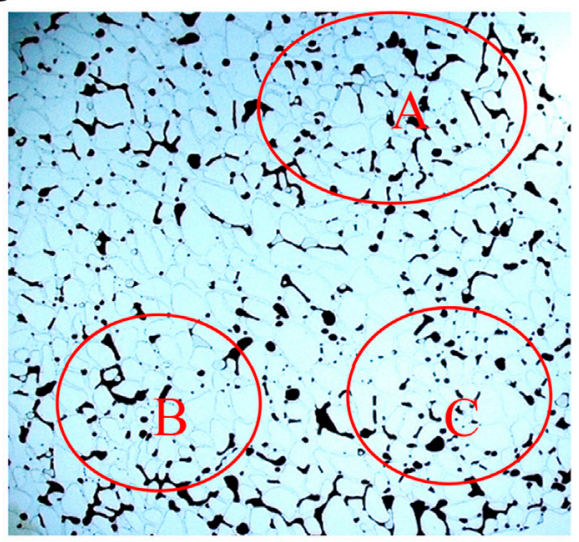

LSW injection

FIGURE 7 | Result of macro-displacement of kaolinite micromodel under (A) HSW injection and (B) LSW injection.

Fig 6. shows the wetting properties of the kaolinite model in HSW and LSW. Difference in the change of surface wetting properties of the model attached with kaolinite under two types of displacement modes can be explained by the diffusion of the double electric layer. In HSW flooding, negatively charged kaolinite and crude oil would be neutralized by cations, the electric double layer between kaolinite and crude oil would become thinner, offsetting the exclusion between oil and clay. Then, the bridge of cations in HSW keeps the crude oil connected with the clay surface, forming a lipophilic porous medium. After LSW flooding, highly mineralized formation water is gradually replaced. The reduction of the strength of ion bridge leads to the diffusion of electric double layer between clay and crude oil, which weakens the bridge of cations in formation water, thus increasing the electrostatic repulsion between clay and crude oil, destroying the adsorption state of crude oil on the surface of clay particles, and transforming wetting properties to a more hydrophilic state. When the electrostatic repulsion is high enough, oil droplets are released from the surface of clay particles and replaced by low salinity water.

Result of the macro-displacement of kaolinite is shown in Fig 7, and oil recovery of A, B, C region in the figure increases greatly. For micromodel attached with kaolinite, in the process of HSW flooding, since pore surface is oil-wetting and oil film stranded on pore is thick, it is not easy to replace the oil. Besides, injected water cannot enter into small throats easily, as a result, a large amount of crude oil was bypassed, resulting in low oil recovery efficiency. In the process of LSW flooding, due to the diffusion of electric double layer and other mechanisms which can lead to the change of wetting properties, the Van der Waals force between clay particles and crude oil was weakened, static repulsion force was enhanced, pore surface changed from oil-wetting into mixed wetting, oil droplets detached from the pore of hydrophilia surface, and crude oil in small throats was displaced, so the recovery rate was significantly improved. 


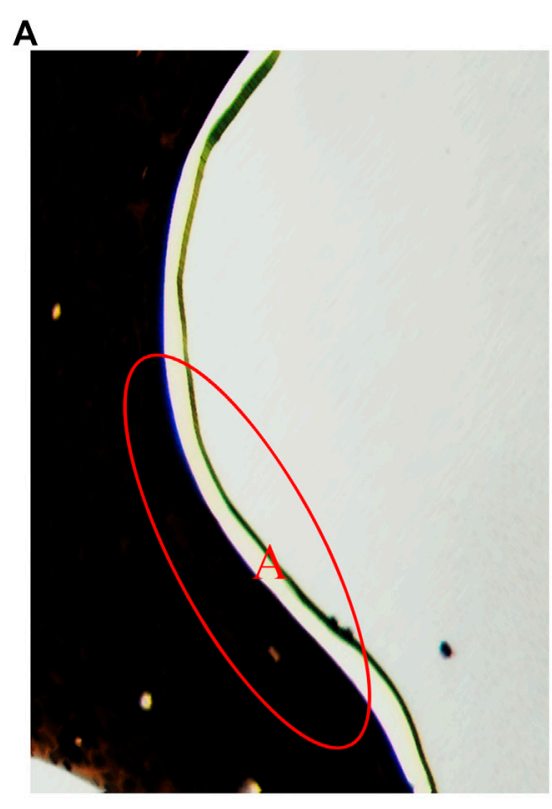

HSW injection

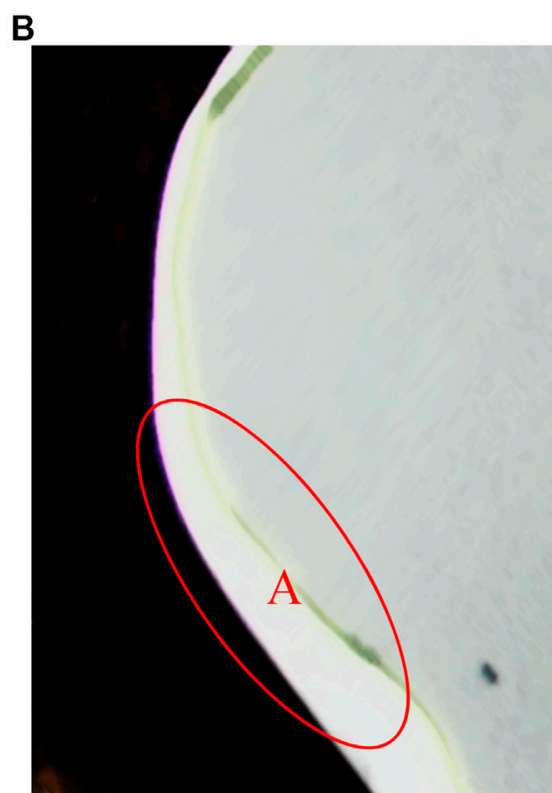

LSW injection

FIGURE 8 | Wetting properties of m ontmorillonite micromodels during (A) HSW injection and (B) LSW injection.

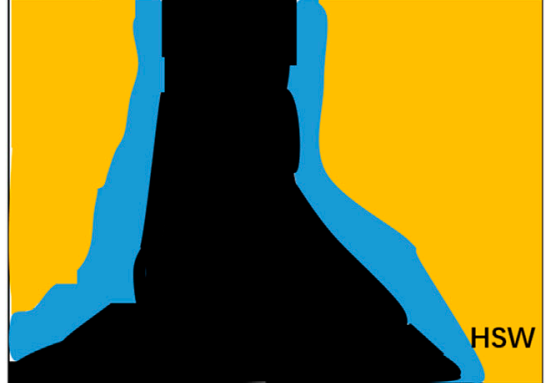

rock

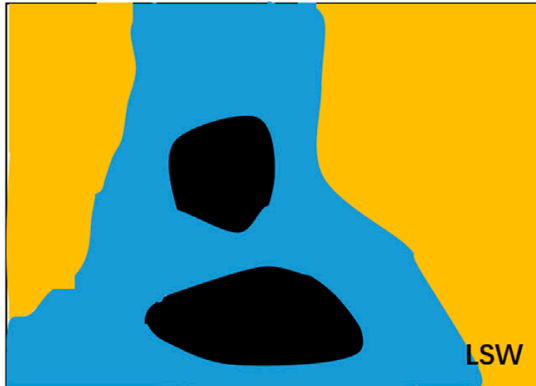

oil

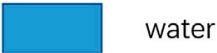

FIGURE 9 | Schematic of oil distribution in HSW and LSW flooding.

\section{Low Salinity Water Flooding in Montmorillonite}

Procedure of the montmorillonite experiment was similar to that of kaolinite and montmorillonite had obvious water-wet due to its weak crystal lattice and cations on the surface.

Micromodel attached with montmorillonite is shown in Fig 8. In the process of HSW flooding, the surface of the pore wall is water wetting, the surface of the water film is thin, and the adsorption capacity of crude oil is strong. In the process of LSW flooding, it can be seen from the figure that the thickness of the water film in the A area increases, the ability to absorb crude oil is weakened, and residual oil in the hole throat becomes more fluid. This difference is caused by the lattice structure of montmorillonite. When low salinity water is injected, low valence cations replace high valence cations between structural unit layers and electric double layer on the clay surface diffuses, causing the increase of the electrostatic repulsion between clay and crude oil and being more hydrophilic.

Although there was no evidence of wettability alteration and the whole system remained water-wet, it had been suggested that polar components of crude oil contacted with a brine phase and became highly elastic under LSW condition. Increased viscoelasticity of water-oil interface hinders the snap-off of the oil into small droplets that would disperse in brine, this 


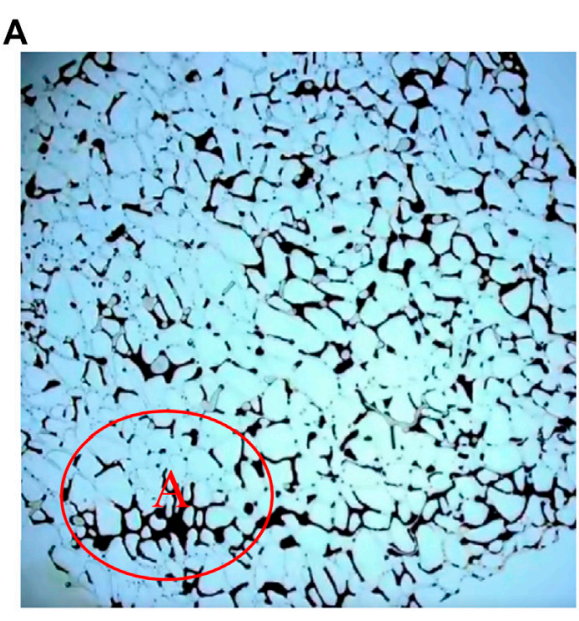

HSW injection

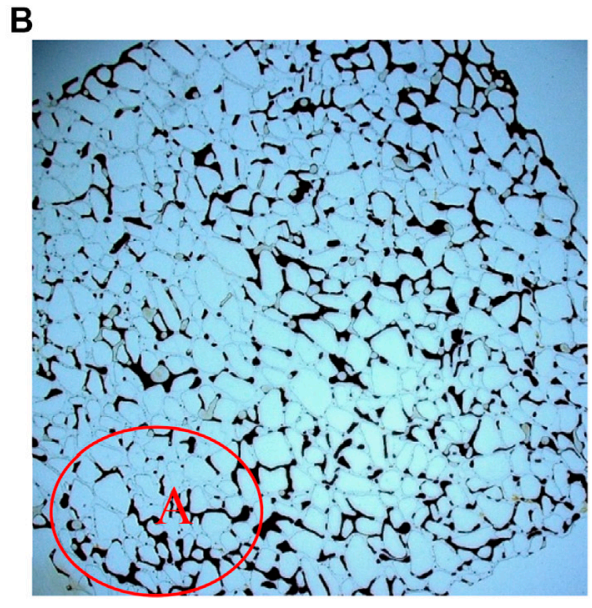

LSW injection

(A) HSW flooding and (B) LSW flooding.

phenomenon is shown in Fig 9. As a result, oil in LSW is more continuous and mobile than that in HSW. Therefore, the viscoelastic characteristic of the water-oil interface may make a critical contribution to the EOR of LSW flooding.

Characteristics of residual oil migration of the micromodel attached with montmorillonite are shown in Fig 9. We can see that in the process of HSW flooding, injected water moves along the pore throat and easy to get stuck. Due to the capillary force, there is a large amount of residual oil in the middle of the hole channel that is illiquid. And we can see that there is a large amount of residual oil in positions $\mathrm{A}, \mathrm{B}$, and $\mathrm{C}$ in the figure. In the process of LSW flooding, residual oil in positions $\mathrm{A}, \mathrm{B}$, and $\mathrm{C}$ is reduced, and it changes from block to beaded, drop-shaped. Capillary force in the whole system no longer dominates, and oil is less stuck in the narrower hole throat. During this process, water is kept at the waterflood front, while only oil phase is moving in front of the waterflood front.

Result of the macro-displacement of montmorillonite micromodel is shown in Fig 10. In this figure, recovery degree is greatly improved only in the A region and it is not obvious enough in other remaining areas. For micromodel attached with montmorillonite, in the HSW flooding process, its result is slightly better than the result of micromodel attached with kaolinite under the same flooding condition since the surface of the montmorillonite pore is water-wetting. In the LSW flooding process, the water-wet characteristic of montmorillonite is enhanced, water film thickens and adsorption capacity of crude oil is reduced, while residual oil has undergone a shift from snap-and-replace to piston-like displacement. However, there is still droplet-like residual oil in the throat.

As for $\mathrm{pH}$ values of input and output. The $\mathrm{pH}$ of input brine was 7 , and the $\mathrm{pH}$ of output after HSW flooding is nearly 9 and is around 7 after LSW flooding. The downward shift in effluent $\mathrm{pH}$ difference between HSW and LSW is traditionally ascribed to the exchange of $\mathrm{H}^{+}$and positive ion on clay surface (Li et al., 2020a; Li et al., 2020b).

\section{CONCLUSIONS}

Through the experiment of micro-seepage characteristics of low salinity water, the surface mechanism of LSW flooding EOR is verified from a microscopic point, and the following conclusions are concluded:

(1) Diffusion happens in double electron layer, ion exchange and wettability changes occur between clay minerals and LSW interfaces, are main mechanisms of LSW flooding EOR and these mechanisms are correlated to each other. Clay minerals undergo ion exchange under the action of low salinity water, which causes the diffusion of the double electron layer, resulting in the change of potential, and the wetting angle changes as a result.

(2) For micromodel attached with kaolinite, in the process of HSW flooding, residual oil is attached to the surface in a membrane-like way, and the oil membrane is thick, so it is not easy to be replaced. In the process of LSW flooding, the membranous residual oil is thin and easy to be replaced. The mechanism of LSW to improve recovery rate is the change of surface wettability, so the residual oil can be replaced easily. There is no wetting transition from lipophilicity to hydrophily for micromodels attached to montmorillonite. The montmorillonite is still water phase wetting. The mechanism of LSW to improve the recovery rate is the further enhancement of water phase wetting and a thicker water membrane. The adsorption state of residual oil in the large hole channel is not obvious, and residual oil in the small hole is changed from columnar form to beaded and dropshaped form. 
(3) In field production, LSW is suitable for reservoirs containing clay minerals. But for reservoirs rich in kaolinite, the lower the mineralization of the water, the better. For reservoirs rich in montmorillonite, there are lots of drop-shaped residual oil left in throat when using LSW flooding, and new methods are needed to recover the remaining oil.

\section{DATA AVAILIABILITY STATEMENT}

The original contributions presented in the study are included in the article/supplementary materials, further inquiries can be directed to the corresponding author.

\section{REFERENCES}

Al Shalabi, E. W., Sepehrnoori, K., and Delshad, M. (2014). Mechanisms behind low salinity water injection in carbonate reservoirs. Fuel 121, 11-19. doi:10. 1016/j.fuel.2013.12.045

Al-Saedi, H. N., Brady, P. V., Flori, R., and Heidari, P. (2018). "Novel insights into low salinity water flooding enhanced oil recovery in sandstone: the clay role study,"in SPE Improved Oil Recovery Conference, Tulsa, OKLA, April 14-18. doi:10.2118/190215-MS

Al-Saedi, H. N., and Flori, R. E. (2018). Enhanced oil recovery of low salinity water flooding in sandstone and the role of clay. Petrol. Explorat. Develop. 45, 927-931. doi:10.1016/S1876-3804(18)30096-X

Amirian, T., Haghighi, M., and Mostaghimi, P. (2017). Pore scale visualization of low salinity water flooding as an enhanced oil recovery method. Energy Fuels. 31, 13133-13143. doi:10.1021/acs.energyfuels.7b01702

Barnaji, M. J., Pourafshary, P., and Rasaie, M. R. (2016). Visual investigation of the effects of clay minerals on enhancement of oil recovery by low salinity water flooding. Fuel 184, 826-835. doi:10.1016/j.fuel.2016.07.076

Bondino, I., Doorwar, S., Ellouz, R., and Hamon, G. (2013). "Visual microscopic investigations about the role of $\mathrm{pH}$ Salinity and clay on oil clay on oil adhesion and recovery," in International Symposium of the Society of Core Analysts, Napa Valley, CA, September 16-19.

Demir, A. B., Bilgesu, H. I., and Hascakir, B. (2016). "The effect of clay and salinity on asphaltene stability," SPE Western Regional Meeting, Anchorage, AK, May 23-26. doi:10.2118/180425-MS

Fogden, A., Kumar, M., Morrow, N. R., and Buckley, J. S. (2011). Mobilization of fine particles during flooding of sandstones and possible relations to enhanced oil recovery. Energy Fuels. 25, 237-242. doi:10.1021/ef101572n

Hilner, E., Andersson, M. P., Hassenkam, T., Matthiesen, J., Salino, P. A., and Stipp, S. L. S. (2015). The effect of ionic strength on oil adhesion in sandstone - the search for the low salinity mechanism. Entific Reports. 5, 9933. doi:10.1038/ srep09933

Hirasaki, G. J. (1991). Wettability: fundamentals and surface forces. SPE Form. Eval. 6 (2), 217-226. doi:10.2118/17367-PA

Kaya, A., Ren, A. H., and Yükselen, Y. (2006). Settling of kaolinite in different aqueous environment. Mar. Georesour. Geotechnol. 24 (3), 203-218. doi:10. $1080 / 10641190600788429$

Kim, C., and Lee, J. (2017). Experimental study on the variation of relative permeability due to clay minerals in low salinity water-flooding. J. Petrol. Sci. Eng. 151, 292-304. doi:10.1016/j.petrol.2017.01.014

Lager, A., Webb, K. J., Black, C. J. J., Singleton, M., and Sorbie, K. S. (2008). Low salinity oil recovery - an experimental investigation. Petrophysics 49 (1), 28-35. https://www.researchgate.net/publication/241783001

Lager, A., Webb, K. J., Collins, I. R., and Richmond, D. M. (2008). "LoSal enhanced oil recovery: evidence of enhanced oil recovery at the reservoir scale," in SPE symposium on improved oil recovery, Tulsa, OKLA, April 20-23. doi:10.2118/ 113976-MS

\section{AUTHOR CONTRIBUTIONS}

XW: Conceptualization, Methodology, Validation, Formal analysis, Writing - Original Draft, Supervision, Project administration, unding acquisition. YZ: Validation, Project administration. WJ: Methodology, Validation, Formal analysis, Writing - Original Draft. ZW: Experimental running. XL: Investigation, Resources. FW: Methodology.

\section{ACKNOWLEDGMENTS}

This study was supported by the Natural Science Foundation of China (Project Number: 51874339)

Li, S., Wang, Q., and Li, Z. (2020a). Stability and flow properties of oilbased foam generated by $\mathrm{CO}_{2}$. SPE J. 25 (1), 416-431. doi:10.2118/ 199339-PA

Li, S., Wang, Q., Zhang, K., and Li, Z. (2020b). Monitoring of CO2 and CO2 oilbased foam flooding processes in fractured low-permeability cores using nuclear magnetic resonance (NMR). Fuel 263-116648. doi:10.1016/j.fuel. 2019.116648

Loahardjo, N., Xie, X., and Morrow, N. R. (2010). Oil recovery by sequential waterflooding of mixed-wet sandstone and limestone. Energy \& Fuels. 24, 5073-5080. doi:10.1021/ef100729b

Myint, P. C., and Firoozabadi, A. (2015). Thin liquid films in improved oil recovery from low-salinity brine. Current Opinion in Colloid \& Interface ence. 20 (2), 105-114. doi:10.1016/j.cocis.2015.03.002

Nasralla, R. A., and Nasr-El-Din, H. A. (2014a). Double-layer expansion: is it a primary mechanism of improved oil recovery by low-salinity waterflooding? SPE Reservoir Eval. Eng. 17 (1), 49-59. doi:10.2118/154334-MS

Nasralla, R. A., and Nasr-El-Din, H. A. (2014b). Impact of cation type and concentration in injected brine on oil recovery in sandstone reservoirs. J. Petrol. Engineer. 122, 384-395. doi:10.1016/j.petrol.2014.07.038

Reed, J., and Mcdonald, A. (2015). "Influence of clay content and type on oil recovery under low salinity waterflooding on north sea reservoirs," in SPE Offshore Europe Conference and Exhibition, Aberdeen, Scotland, September 8-11. doi:10.2118/175506-MS

Stanislav, J., Susan, S., and Nicolas, B. (2018). Adsorption of organic ligands on low surface charge clay minerals: the composition in the aqueous interface region. Phys. Chem. Chem. Phys. 20, 17226-17233. doi:10.1039/C8CP01189C

Tammy, A., and Manouchehr, H. (2018). Impact of clay type and water composition on low salinity water injection - visualisation approach APPEA J. 58 (1), 51-59. doi:10.1071/AJ17076

Tang, G. Q., and Morrow, N. R. (1999). Influence of brine composition and fines migration on crude oil/brine/rock interactions and oil recovery. J. Petrol. Engineer. 24 (2), 99-111. doi:10.1016/S0920-4105(99)00034-0

Tina, P., Aleksandr, M., Zahra, A., Oline, F. G., Marie, M. G., Skule, S., et al. (2018). Role of kaolinite clay minerals in enhanced oil recovery by low salinity water injection. Energy Fuels. 32 (7), 7374-7382. doi:10.1021/acs. energyfuels.8b00790

Xie, Q., Saeedi, A., Pooryousefy, E., and Liu, Y. (2016). Extended DLVO-based estimates of surface force in low salinity water flooding. J. Mol. Liq. 221, 658-665. doi:10.1016/j.molliq.2016.06.004

Yousef, A. A., Al-Saleh, S., Al-Kaabi, A., and Al-Jawfi, M., (2011). Laboratory investigation of the impact of injection-water salinity and ionic content on oil recovery from carbonate reservoirs. SPE Reservoir Eval. Eng. 14 (5), 578-593. doi:10.2118/137634-PA

Zhang, L., Zhang, J., Wang, Y., Yang, R., Zhang, Y., Gu, J., et al. (2018). Experimental investigation of low salinity water flooding in a lowpermeability oil reservoir. Energy Fuels. 32 (3), 3108-3118. doi:10.1021/acs. energyfuels.7b03704

Zhang, Y., Xie, X., and Morrow, N. (2007). "Waterflood performance by injection of brine with different salinity for reservoir cores," in SPE 
Annual Technical Conference and Exhibition, Anaheim, CA, November 11-14. doi:10.2118/109849-MS

Conflict of Interest: The authors declare that the research was conducted in the absence of any commercial or financial relationships that could be construed as a potential conflict of interest.
Copyright $\odot 2020$ Wei, Zhang, Jiang, Wang, Li and Wu. This is an open-access article distributed under the terms of the Creative Commons Attribution License (CC BY). The use, distribution or reproduction in other forums is permitted, provided the original author(s) and the copyright owner(s) are credited and that the original publication in this journal is cited, in accordance with accepted academic practice. No use, distribution or reproduction is permitted which does not comply with these terms. 